

Open Access

Asian Australas. J. Anim. Sci.

Vol. 29, No. 7 : 1052-1059 July 2016

http://dx.doi.org/10.5713/ajas.15.0757

www.ajas.info

pISSN 1011-2367 elSSN 1976-5517

\title{
Red Color Light at Different Intensities Affects the Performance, Behavioral Activities and Welfare of Broilers
}

\author{
D. Senaratna*, T. S. Samarakone ${ }^{1}$, and W. W. D. A. Gunawardena \\ Department of Animal Science, Faculty of Agriculture, University of Ruhuna, \\ Mapalana, Kamburupitiya 81100, Sri Lanka
}

\begin{abstract}
Red light (RL) marked higher weight gain (WG) and preference of broilers compared to other light colors. This study aimed to investigate how different intensities of RL affect the performance, behavior and welfare of broilers. RL treatments were T1 $=$ high intensity (320 lux), T2 = medium intensity (20 lux); T3 = dim intensity ( 5 lux ), T4 = control/white light at (20 lux) provided on 20L:4D schedule and T5 = negative control; 12 hours dark: 12 hours day light. Cobb strain broilers were used in a Complete Randomize Design with 6 replicates. WG, water/feed intake, feed conversion ratio (FCR), mortality, behavior and welfare were assessed. At $35 \mathrm{~d}$, significantly $(\mathrm{p}<0.05)$ highest body weight $(2,147.06 \mathrm{~g} \pm 99)$ was recorded by T3. Lowest body weight $(1,640.55 \mathrm{~g} \pm 56)$ and FCR $(1.34)$ were recorded by T5. Skin weight was the only carcass parameter showed a significant $(\mathrm{p}<0.05)$ influence giving the highest $(56.2 \mathrm{~g})$ and the lowest $(12.6 \mathrm{~g})$ values for T5 and T1 respectively. Reduced welfare status indicated by significantly (p<0.05) higher foot pad lesions, hock burns and breast blisters was found under T3, due to reduced expression of behavior. Highest walking $(2.08 \% \pm 1 \%)$ was performed under T1 in the evening during 29 to 35 days. Highest dust bathing (3.01\% $\pm 2 \%$ ) was performed in the morning during 22 to 28 days and highest bird interaction (BI) $(4.87 \% \pm 4 \%)$ was observed in the evening by T5 during 14 to 21 days. Light intensity $\times$ day session $\times$ age interaction was significantly $(\mathrm{p}<0.05)$ affected walking, dust bathing and BI. Light intensity significantly $(\mathrm{p}<0.05)$ affected certain behaviors such as lying, eating, drinking, standing, walking, preening while lying, wing/leg stretching, sleeping, dozing, BI, vocalization, idling. In conclusion, birds essentially required provision of light in the night for better performance. Exposed to 5 lux contributed to higher WG, potentially indicating compromised welfare status. Further researches are suggested to investigate RL intensity based lighting regimen that favors for both production and welfare of Broilers. (Key Words: Behavior, Broilers, Intensities, Performance, Red-light, Welfare).
\end{abstract}

\section{INTRODUCTION}

Color is an important aspect of light that has been considered as a management tool in poultry production. Prayitno and Phillips (1997) observed a Ross strain of broiler that was reared in red, blue, green and white color light. In that study bird behavior was above all affected, but not growth rate while in another study, Prayitno et al. (1997), growth rate was significantly impacted. For the most part birds exposed to red and white light were more

\footnotetext{
* Corresponding Author: D. Senaratna. Tel: +94-41-2292200, Fax: +94-41-2292384, E-mail: dulcysenaratna@gmail.com

1 Department of Animal Science, Faculty of Agriculture, University of Peradeniya, Peradeniya 20400, Sri Lanka. Submitted Sept. 9, 2015; Revised Nov. 2, 2015; Accepted Dec. 15, 2015
}

active, in that walking, standing, drinking, aggression, and wing stretching increased with intensity in red light (RL) but not blue light. Also the superior activity seems to have resulted in greater sleep in these birds, meanwhile the birds in the green and blue lights spent relatively more time sitting or dozing. The authors concluded that the inability of increased intensities of blue light to increase standing and walking suggests the sensitivity of long wavelength light by the pineal gland is essential to the effect on activity. The directional collective response of increased feeding time in green and blue light for male birds and white light for the female birds, also heavier bone along with a filled crop and gizzard content in the green and blue light does not affect growth at the end of the grower phase. It appears that when light is offered for an extended period to the finisher phase, 
the effect of RL relative to growth is realized.

Red light (780 to $622 \mathrm{~nm}$ ) showed numerous potential benefits in Broilers. On a one hand higher weight gain (WG) could be achieved when providing during early stages (Prayitno et al., 1997; Senaratna et al., 2011). On the other hand, the highest preference was recorded for RL especially in the night compared to green, blue and white color lights (Senaratna et al., 2010; 2012).

There are many potential welfare benefits of improving activity of broiler chicken. Increased movements may improve bone development, litter condition and prevent skin lesions on the hocks, feet and breast, normally caused by prolonged sitting on poor quality litter. Several studies have focused upon ways of increasing activity. It was found that broilers were more active in RL (more ground pecking, wing stretching) and white (more walking) than either in green or blue light of 30 lux (Prayitno et al., 1997). Rearing broilers in bright RD early in life increased activity and decreased leg disorders compared to rearing in dim intensity (DI) blue light. Further, exposure to bright RL in the first 16 d alleviated lameness and gait abnormality problems (Prayitno et al., 1997).

It is relatively well researched with normal incandescent light intensities (LIs) with a primary emphasis on production and health (Lien et al., 2007; Blatchford et al., 2009) where the impact on production traits has found to be either small or lacking (Deep et al., 2010). But relatively few studies have been conducted to examine the effect on broiler behavior, a key indicator of bird welfare. The expression of behaviors has been found to be reduced with exposure to DI as found by Alvino et al. (2009) for 5 lux and Newberry et al. (1988) for 6 lux vs 180 lux. Despite all the facts, the use of DI for commercially housed broilers is common. Though there are many potential benefits of RL for broilers in terms of production and welfare, no experiments conducted to investigate how different intensities of RL affect upon them. Therefore, there is a vacuum to be filled before come to a conclusion for including RL into management plans. It was hypothesized that RL at different illuminance affects behavior of broilers and potentially their production and welfare. The aim of this study was to investigate the effects of incandescent RL at different intensities (high, medium, dim) on production performance, behavior and welfare status of broilers.

\section{MATERIALS AND METHODS}

\section{Birds and rearing environment}

The research protocol has been approved by the Research Ethics Committee of the Faculty of Agriculture, University of Ruhuna, Sri Lanka. Hundred, day old broiler chicks (Cobb) were obtained from a local hatchery and brooded under normal brooding light (60 lux) up to $14 \mathrm{~d}$. Birds were weighed using an electronic balance (Avery Berkel, model SL 6405, Birmingham England, Max. 3 kg, Min. $1 \mathrm{~g}$ ) and randomly assigned 3 birds per each of the 30 experimental cages $(90 \mathrm{~cm} \times 60 \mathrm{~cm})$ by balancing weight. Light treatments; $\mathrm{T}_{1}$ (320 lux; high intensity red [HR]), $\mathrm{T}_{2}$ (20 lux; medium intensity red [MR]), $\mathrm{T}_{3}$ (5 lux; dim intensity red [DR]), $\mathrm{T}_{4}$; (control/20 lux; medium intensity white [WT]) at night including $12 \mathrm{~h}$ of day light and $\mathrm{T}_{5}$; the negative control; $12 \mathrm{~h}$ day light:12 h dark (0 lux) given 14 to $35 \mathrm{~d}$, were arranged in a complete randomize design with 6 replicates. Birds were provided with commercial feeds (CIC, Colombo, Sri Lanka); broiler starter (metabolizable energy $[\mathrm{ME}]=3,000 \mathrm{kcal} / \mathrm{kg}$, crude protein $[\mathrm{CP}]=22 \%$ ); broiler finisher $(\mathrm{ME}=3,100 \mathrm{kcal} / \mathrm{kg}, \mathrm{CP}=20 \%)$ and water ad libitum.

Chicks were brooded under $23 \mathrm{~h}$ brooding light (60 lux) up to $14 \mathrm{~d}$. From $14 \mathrm{~d}$ to $35 \mathrm{~d}$, birds were exposed to 5 different LI treatments. All treatments consist of $12 \mathrm{~h}$ day light. RL and white light were provided on 20 hours light:4 hours dark schedule. Illumination was provided by $5 \mathrm{~W}$ incandescent bulbs. The LI was recorded approximately at the bird's eye height, 3 times each week at 3 positions in each experimental cage using a digital light meter (Acklands-Grainger Inc., Richmond Hill, ON, Canada). Dimming bulbs were done by dimmer switches.

\section{Assessment of performance}

The body weight (BW) of birds was recorded individually at the start of the experiment and subsequently at the end of every week. All the birds were weighed using an electrical weighing balance and the mean weights were calculated. Water/feed intakes (WFI) were measured at the end of each week and daily WFI were calculated for relevant periods. The WFI were recorded by subtracting the weight of the leftover feed/water. Records of weekly feed consumption and WG were used to calculate the feed conversion ratio $(\mathrm{FCR})(\mathrm{FCR}=$ feed consumed/live $\mathrm{WG})$. Mortality records were maintained throughout the experimental period.

\section{Assessment of behavior in different red light intensity environments}

The undisturbed behavior of the birds was recorded for 3 consecutive hours in the morning, evening and night sessions for 4 days a week by adopting scan sampling method (Martin and Bateson, 1993). For this, a well defined broiler ethogram was used to minimize the chances of errors in diagnosing a particular behavior. Twenty two common behaviours performed by broilers were evaluated. Behaviours were evaluated on 3 focal birds/pen, by direct visual scans for 15 minutes intervals. It was recorded the number of birds in each experimental unit engaged in each 
of the activity defined by the ethogram.

\section{Assessment of welfare}

Lameness of the birds was assessed using "latency to lie" test (LTL) as described by Weeks et al. (2002). Two birds from each experimental cage were randomly taken for LTL test at $35 \mathrm{~d}$. Birds were placed in a water proof test pen which was flooded with a shallow layer $(30 \mathrm{~mm})$ of water. As chickens do not prefer to sit in water, flooding the pen motivates the birds to stand up. The time taken for each bird to lie down was recorded. Presence of foot pad dermatitis (FPD), hock burning damage (HBD) and breast blisters (BB) were assessed using an internationally accepted score system used by Kestin et al. (1992). HBD and BB were scored on a 4 point scale ( 0 , no visible damage to skin; 1 , signs of skin deterioration without redness; 2 , signs of skin deterioration with presence of redness; and 3, an obvious lesion or score). FPD was scored on a three point scale where 0 described normal footpads without lesions, whereas a score of 2 was given for obvious scores on the footpads (Ekstrand et al., 1998a). Once each bird had been assessed for leg health and weighed, it was marked with a tag to avoid recapture and released back into the flock before the next bird was captured and assessed. In total, 12 birds $(67 \%)$ were assessed from each of the treatment.

\section{Statistical analysis}

Parameters were tested for normality prior to analysis for statistical significance of treatment differences by analysis of variance, using Proc. general linear model of Statistical Analysis Software (SAS, SAS Institute, 2003 Inc. Release 9.1.3). The data thus were subjected to one way analysis of variance technique with completely randomized design. Treatment means were compared by Duncan Multiple Range Test and the level of significance was fixed at $\mathrm{p} \leq 0.05$. Percentage behaviour data were first log transformed and then analyzed. The difference between treatment means was examined by including treatment, age, session of the day as main effects and all interactions. Scores given for lameness, FPD, BB, and HBD were analyzed using Kruscal-Wallis test of the statistical package Minitab.

\section{RESULTS AND DISCUSSION}

\author{
Weight gain, feed conversion ratio, mortality and \\ carcass evaluation data
}

The BWs were almost same when introduced into the experimental cages at $14 \mathrm{~d}$. After $21 \mathrm{~d}$, negative control marked significantly $(p<0.05)$ lower $\mathrm{BWs}$ compared to other treatments. Increasing BW under DR compared to HR reflects that there is a beneficial effect of reducing intensity from 320 to 20, 5 lux respectively. At the time of slaughter $(35 \mathrm{~d})$, significantly $(\mathrm{p}<0.05)$ the highest $\mathrm{BW}$ was recorded by DR and the lowest by negative control (Table 1). Higher intensities of RL (>5 lux) and WT resulted comparatively lower BW. Previous research also revealed that the BW of broiler chickens were greater under dim intensities as Wathes et al. (1982) compared 63 lux to 1,290 lux. Similarly 2.7 lux gained more BW than reared at 21.5 lux as found by Downs et al. (2006) indicating most of the previous findings are in accordance with our findings. Bright light might have stimulated the activity of broilers to the extent that they utilized more energy for maintenance instead of growth. But, in contrast, Newberry et al. (1988) found that no influence of light intensity (LI) (180 vs 6 lux) on BW. Denbow et al. (1990), Hullet et al. (1992) also reported that there was no effect of LI on WG. But birds kept under lower LIs in the present study contributed to marginally increased WG than those kept under higher LIs (Table 2).

No significant differences were observed among LI treatments for total FCR. Reason for significantly $(p<0.05)$ lowest FCR marked by negative control may be both reduced WG and feed intake (FI). Our results were in accordance with the findings of Buyse et al. (1996) who tested for 5 vs 51 lux and Lien et al. (2008) for 1.75 vs 162 lux who envisaged increasing LI had no significant effect on FCR. But, Downs et al. (2006) stated that lower intensities may improve FCR because of a reduction in activities and stimulating muscular growth. Deviation of our results may be due to over $12 \mathrm{~h}$ of day light period which might have outdone the effect LI treatments. The mortality (\%) was $5.55 \% \pm 3.6 \%$ for both MR or WT treatments during 3 rd and 5 th weeks, respectively. Mortality

Table 1. Effect of different light intensity treatments on body weight

\begin{tabular}{|c|c|c|c|c|c|c|}
\hline \multirow[b]{2}{*}{ Age } & \multicolumn{5}{|c|}{ Light intensity treatment and body weight(g) } & \multirow{2}{*}{$\begin{array}{c}\text { LSD at } 5 \% \\
\text { level }\end{array}$} \\
\hline & $\begin{array}{c}\text { High } \\
(320 \text { lux })\end{array}$ & $\begin{array}{l}\text { Medium } \\
(20 \text { lux })\end{array}$ & $\begin{array}{c}\text { Dim } \\
(5 \operatorname{lux})\end{array}$ & $\begin{array}{c}\text { Control/white } \\
\text { (20 lux) }\end{array}$ & $\begin{array}{c}\text {-VEC } \\
(12 \mathrm{D}: 12 \mathrm{~L})\end{array}$ & \\
\hline $14 \mathrm{~d}$ & $473.22 \pm 14.8$ & $472.00 \pm 21.4$ & $479.88 \pm 16.8$ & $467.16 \pm 13.8$ & $441.45 \pm 29.1$ & 14.26 \\
\hline $21 \mathrm{~d}$ & $849.06 \pm 46.7$ & $838.56 \pm 31.3$ & $842.72 \pm 41.4$ & $859.22 \pm 40.9$ & $724.66 \pm 56.3$ & \\
\hline $28 \mathrm{~d}$ & $1,472.95 \pm 78.9$ & $1,466.56 \pm 76.7$ & $1,499.44 \pm 44.2$ & $1,481.55 \pm 86.7$ & $1,303.38 \pm 103.9$ & \\
\hline $35 \mathrm{~d}$ & $2,042.84 \pm 150.1$ & $2,036.22 \pm 105.7$ & $2,147.06 \pm 99.7$ & $2,035.61 \pm 137.9$ & $1,640.55 \pm 56.4$ & \\
\hline
\end{tabular}

-VEC, negative control, LSD, least significant difference.

Negative control consisted of $12 \mathrm{~h}$ of dark period and $12 \mathrm{~h}$ of light period. 
Table 2. Effect of different red light intensity treatments on weight gain, FCR, water/feed intakes and W:F ratio

\begin{tabular}{|c|c|c|c|c|c|c|}
\hline Parameter and age & $\begin{array}{c}\text { High } \\
(320 \text { lux })\end{array}$ & $\begin{array}{l}\text { Medium } \\
\text { (20 lux) }\end{array}$ & $\begin{array}{l}\text { Dim } \\
(5 \operatorname{lux})\end{array}$ & $\begin{array}{l}\text { Control/white } \\
\text { (20 lux) }\end{array}$ & $\begin{array}{c}\text {-VEC } \\
(12 \mathrm{D}: 12 \mathrm{~L})\end{array}$ & $\mathrm{p}$ \\
\hline \multicolumn{7}{|c|}{ Weight gain (g/bd/week) } \\
\hline $14-21 \mathrm{~d}$ & $375.83^{\mathrm{a}}$ & $366.56^{\mathrm{a}}$ & $362.83^{\mathrm{a}}$ & $392.06^{\mathrm{a}}$ & $283.22^{\mathrm{b}}$ & 0.0001 \\
\hline $22-28 d$ & $623.89^{\mathrm{a}, \mathrm{b}}$ & $628.00^{\mathrm{a}, \mathrm{b}}$ & $656.72^{\mathrm{a}}$ & $622.34^{\mathrm{a}, \mathrm{b}}$ & $578.72^{\mathrm{b}}$ & 0.0262 \\
\hline $29-35 d$ & $569.89^{\mathrm{a}}$ & $569.67^{\mathrm{a}}$ & $647.61^{\mathrm{a}}$ & $554.05^{\mathrm{a}}$ & $337.17^{b}$ & 0.0001 \\
\hline Total WG & $1,569.61^{\mathrm{a}}$ & $1,564.22^{\mathrm{a}}$ & $1,667.17^{\mathrm{a}}$ & $1,568.44^{\mathrm{a}}$ & $1,199.11^{\mathrm{b}}$ & 0.0001 \\
\hline \multicolumn{7}{|l|}{ FCR } \\
\hline $14-21 d$ & 1.53 & 1.46 & 1.49 & 1.47 & 1.54 & 0.4869 \\
\hline $22-28 d$ & $1.02^{\mathrm{b}}$ & $1.03^{\mathrm{b}}$ & $1.03^{\mathrm{b}}$ & $1.03^{\mathrm{b}}$ & $1.08^{\mathrm{a}}$ & 0.0135 \\
\hline $29-35 d$ & $1.62^{\mathrm{b}}$ & $1.54^{\mathrm{b}}$ & $1.59^{\mathrm{b}}$ & $1.57^{\mathrm{b}}$ & $1.34^{\mathrm{a}}$ & 0.0005 \\
\hline Total FCR & $1.35^{\mathrm{a}}$ & $1.31^{\mathrm{a}}$ & $1.34^{\mathrm{a}}$ & $1.32^{\mathrm{a}}$ & $1.26^{\mathrm{b}}$ & 0.0046 \\
\hline \multicolumn{7}{|l|}{ Feed intake $(\mathrm{g} / \mathrm{bd} / \mathrm{d})$} \\
\hline $14-21 \mathrm{~d}$ & $82.24^{\mathrm{a}}$ & $76.48^{\mathrm{a}}$ & $77.39^{\mathrm{a}}$ & $82.27^{\mathrm{a}}$ & $62.43^{\mathrm{b}}$ & 0.0003 \\
\hline $22-28 d$ & $145.38^{\mathrm{a}}$ & $144.06^{\mathrm{a}, \mathrm{b}}$ & $149.32^{\mathrm{a}}$ & $145.94^{\mathrm{a}}$ & $133.06^{\mathrm{b}}$ & 0.0699 \\
\hline $29-35 d$ & $138.26^{\mathrm{a}, \mathrm{b}}$ & $145.17^{\mathrm{a}}$ & $149.50^{\mathrm{a}}$ & $143.18^{\mathrm{a}}$ & $128.78^{\mathrm{b}}$ & 0.0146 \\
\hline Total feed intake & $365.88^{a}$ & $365.71^{\mathrm{a}}$ & $376.21^{\mathrm{a}}$ & $371.39^{\mathrm{a}}$ & $324.27^{\mathrm{b}}$ & 0.0027 \\
\hline \multicolumn{7}{|l|}{ Water intake $(\mathrm{g} / \mathrm{bd} / \mathrm{d})$} \\
\hline $14-21 d$ & $182.48^{\mathrm{a}, \mathrm{b}}$ & $167.36^{\mathrm{b}}$ & $183.58^{\mathrm{a}, \mathrm{b}}$ & $192.06^{\mathrm{a}}$ & $143.94^{\mathrm{c}}$ & 0.0012 \\
\hline $22-28 d$ & $366.64^{\mathrm{b}}$ & $373.67^{b}$ & $464.76^{\mathrm{a}}$ & $397.79^{\mathrm{a}, \mathrm{b}}$ & $356.52^{\mathrm{b}}$ & 0.0322 \\
\hline $29-35 d$ & 322.5 & 300.27 & 305.47 & 323.12 & 299.17 & 0.9418 \\
\hline Total water intake & 871.63 & 841.29 & 953.81 & 912.96 & 799.63 & 0.2222 \\
\hline \multicolumn{7}{|l|}{$\mathrm{W}: \mathrm{F}$ ratio } \\
\hline $14-21 d$ & 2.22 & 2.19 & 2.39 & 2.33 & 2.31 & 0.4815 \\
\hline $22-28 d$ & $2.52^{\mathrm{b}}$ & $2.59^{\mathrm{b}}$ & $3.11^{\mathrm{a}}$ & $2.72^{\mathrm{a}, \mathrm{b}}$ & $2.67^{\mathrm{b}}$ & 0.0489 \\
\hline $29-35 d$ & 2.35 & 2.07 & 2.05 & 2.25 & 2.32 & 0.7091 \\
\hline Total W:F & 2.3 & 2.3 & 2.5 & 2.4 & 2.4 & 0.6623 \\
\hline
\end{tabular}

FCR, feed conversion ratio; $\mathrm{W}: \mathrm{F}$, water:feed ratio.

${ }^{\mathrm{a}-\mathrm{c}}$ Superscripts within a raw bearing different letters are significantly $(\mathrm{p}<0.05)$ differ.

differences attributable to lighting programs were often not observed unless lighting levels approach 20 lux. These results were in accordance with Newberry et al. (1988) and Buyse et al. (1996) who observed an increase in mortality due to increased LI.
Most carcass characteristics were not affected by LI except skin weight (Table 3). Birds exposed to negative control showed the highest skin weight and HR treated birds showed the lowest. This may be due to exposure to 12 $\mathrm{h}$ of dark period inactivated the birds as indicated by higher

Table 3. Effect of different light intensity treatments on carcass parameters

\begin{tabular}{|c|c|c|c|c|c|c|}
\hline \multirow{2}{*}{$\begin{array}{l}\text { Carcass parameter }{ }^{1} \\
\text { (Weight, g) }\end{array}$} & \multicolumn{5}{|c|}{ Treatment } & \multirow[b]{2}{*}{$\mathrm{p}$} \\
\hline & $\begin{array}{c}\text { HR } \\
\text { (320 lux) }\end{array}$ & $\begin{array}{c}\text { MR } \\
(20 \operatorname{lux})\end{array}$ & $\begin{array}{c}\text { DR } \\
(5 \operatorname{lux})\end{array}$ & $\begin{array}{c}\text { Control/WT } \\
(20 \text { lux })\end{array}$ & $\begin{array}{c}\text {-VEC } \\
(12 \mathrm{D}: 12 \mathrm{~L})\end{array}$ & \\
\hline Carcass wt. & $1,530.50$ & $1,616.00$ & $1,656.00$ & $1,519.00$ & $1,333.50$ & 0.39 \\
\hline Gizzard & 5.50 & 6.00 & 7.50 & 7.00 & 4.50 & 0.25 \\
\hline Crop & 33.00 & 36.50 & 35.50 & 34.00 & 27.00 & 0.38 \\
\hline Liver & 8.00 & 9.00 & 8.50 & 9.00 & 7.50 & 0.39 \\
\hline Heart & 153.50 & 128.50 & 138.50 & 128.50 & 123.00 & 0.47 \\
\hline Skin & $12.6^{\mathrm{e}}$ & $24.3^{\mathrm{d}}$ & $31.6^{\mathrm{c}}$ & $42.3^{\mathrm{b}}$ & $56.2^{\mathrm{a}}$ & 0.0001 \\
\hline Intestine & 77.50 & 87.00 & 84.75 & 84.75 & 72.25 & 0.37 \\
\hline Bone wt. (Thigh+Drum stick) & 254.00 & 271.00 & 296.00 & 251.00 & 269.00 & 0.44 \\
\hline $\begin{array}{l}\text { Muscle wt. }^{2} \\
\text { (Thigh+Drum stick) }^{\text {This }}\end{array}$ & 127.00 & 135.50 & 148.00 & 125.50 & 134.50 & 0.44 \\
\hline
\end{tabular}

HR, high intensity red; MR, medium intensity red; DR, dim intensity red; WT, medium intensity white; -VEC, negative control.

${ }^{1}$ Avg. of 12 birds per treatment, overall median $=0.00$.

${ }^{2}$ As a $\%$ of carcass wgt.

${ }^{\mathrm{a}-\mathrm{e}}$ Superscripts within a raw bearing different letters are significantly $(\mathrm{p}<0.05)$ differ. 
sleeping under negative control which might have resulted higher fat deposition in the skin. WT and DR received second and third places respectively. Charles et al. (1992) also found that DR ( 5 lux) resulted in increased fat and decreased protein levels of the carcass and suggested that this might be due to decreased activity of birds kept in DR.

\section{Water intake, feed intake, and water:feed ratio}

No significant difference recorded for FI among LI treatments, whereas negative control treated birds showed a significant $(\mathrm{p}<0.05)$ reduction in FI (Table 2$)$. These results were in line with the studies of some former scientists. Similar to our findings, Newberry et al. (1988) compared two levels (6 and 180 lux) of LI and found that FI were the same for both levels. But Lien et al. (2008) found that FI increased proportionally by providing 1.75 vs 162 lux of LI. The contradiction in the results may be attributed to a wide range of LI applied in the present study (0 to 320 lux) instead of 1.75 to 162 lux applied by Lien et al. (2008). Previous research consistently shows that LI from 1 to 150 lux does not affect broiler FI. However, from the above results it can be seen that LI ranging from 5 to 40 lux have a little or no effect on FI. Hence the electricity can be saved by providing lower LI (5 lux) instead of higher (40 lux) without any adverse effect on the FI. But, welfare consequences must be considered when applying dim light. Comparatively up to $28 \mathrm{~d}$ higher water intakes recorded by $\mathrm{WT}$ and the DR and significantly $(\mathrm{p}<0.05)$ highest $\mathrm{W}: \mathrm{F}$ intake was also recorded by DR. This may be related to increased physiological functions leading to highest BW recorded by DR.

\section{Welfare assessment}

There was no significant difference among treatments for LTL test results. But higher average FPD (1.00), HBD (1.00) and BB (1.00) showed by both DR and negative control treated birds. HR treated birds recorded neither FPD nor BB as they were more active under high LI. Previous research has shown that increasing broiler activity by reducing stocking density and providing a natural photoperiod resulted in decreased incidence of FPD (Ferrente et al., 2006). The increased incidence of ulcerative foot pad lesions with decreasing LI is likely due to more time spent resting, thus resulting in increased contact time between the foot and litter as suggested by Blatchford et al. (2009). Our research has also found increased resting at low LI and therefore supports this suggestion. The incidence of ulcerative lesions is of greater significance in the modern broiler industry as these wounds are undoubtedly painful and result in reduced welfare of broilers.

\section{Behavior under different intensities of red light environments}

Effect of LI $\times$ session of the day $\times$ age interaction was significant on walking (Wk), dust bathing (Db), sleeping ( $\mathrm{Sl}$ ) and bird interaction (BI) behaviors. RL intensities alone affected (60\%) of the behaviors such as lying (Ly), eating (Et), drinking (Dr), standing (St), Wk, preening while Ly (Pr/Ly), wing/leg stretching (W/Ls), Sl, dozing, BI, vocalization and idling (Table 4). Kristensen et al. (2002)

Table 4. Level of significance of the effect of different intensities of red light treatment (T), age (AG), session of the day (SD) and their interactions on different behaviors

\begin{tabular}{|c|c|c|c|c|c|c|c|}
\hline Behaviour & $\mathrm{T}$ & $\mathrm{AG}$ & SD & $\mathrm{T} \times \mathrm{AG}$ & $\mathrm{T} \times \mathrm{SD}$ & $\mathrm{T} \times \mathrm{AG} \times \mathrm{SD}$ & EMS \\
\hline Lying & $* * * *$ & $* * *$ & $* * * *$ & NS & $* *$ & NS & 11.30 \\
\hline Eating & $* * *$ & $* * *$ & $* * * *$ & $* *$ & $* * * *$ & NS & 4.35 \\
\hline Drinking & $* * * *$ & NS & $* *$ & $* *$ & $* *$ & NS & 2.41 \\
\hline Standing & $* * * *$ & $* * * *$ & $* * * *$ & $* *$ & $* *$ & NS & 5.96 \\
\hline Walking & $* * * *$ & $* * * *$ & $* * * *$ & $* * * *$ & $* * * *$ & $* * * *$ & 0.00 \\
\hline Preening/lying & $* * * *$ & $* * * *$ & $* * * *$ & NS & NS & NS & 2.45 \\
\hline Preening/standing & NS & $* * * *$ & NS & NS & $* * * *$ & NS & 1.52 \\
\hline Wing leg stretching & $* *$ & $* *$ & NS & NS & NS & NS & 0.95 \\
\hline Dust bathing & NS & $* * * *$ & $* * * *$ & NS & NS & $* * *$ & 1.34 \\
\hline Scratching floor & NS & $* *$ & $* * *$ & $* *$ & NS & NS & 0.63 \\
\hline Sleeping & $* * * *$ & NS & $* * * *$ & $* * * *$ & $* * * *$ & $* * * *$ & 6.53 \\
\hline Dozing & $* * * *$ & $* * * *$ & $* * * *$ & NS & NS & NS & 1.97 \\
\hline Wing flapping & NS & $* *$ & $*$ & NS & NS & NS & 0.76 \\
\hline Litter eating & NS & $* * *$ & $* * * *$ & NS & $* *$ & NS & 1.29 \\
\hline Bird Interaction & $* *$ & $* * * *$ & $* * *$ & NS & $* * *$ & $* * * *$ & 1.00 \\
\hline Vocalization & $* * * *$ & NS & $* *$ & $* *$ & $* *$ & NS & 0.54 \\
\hline Idling & $* *$ & NS & $* * *$ & NS & NS & NS & 1.27 \\
\hline Other & NS & NS & $* *$ & NS & NS & NS & 0.49 \\
\hline
\end{tabular}

EMS, error mean square.

${ }^{* *} \mathrm{p}<0.01, * * * \mathrm{p}<0.001, * * * * \mathrm{p}<0.0001$, NS, not significant $(\mathrm{p}>0.05)$. 
supported our findings as they found broiler behavior is strongly affected by LI via affecting their visible acuity. Producers regularly use modern electronic systems to increase LI for short periods during grow-out to increase exercise and thereby reduce skeletal and metabolic disorders. Searched literature, however, portrays conflicting evidence. Further proving our results, Newberry et al. (1985) reported increased activity in brighter (6 to 12 lux) vs darker (0.5 lux) areas within pens. A subsequent study, Newberry et al. (1988) used constant LI treatments that ranged from 0.1 to 100 lux. But the results suggested that as LI increased, activity was decreased with each incremental increase in age.

Irrespective of the age, Sl was the most dominant behavior of all treatments where negative control treated birds marked the highest. Birds exposed to other LI treatments showed decreasing trend of S1 up to 21 to $28 \mathrm{~d}$ and then increased. Also it was found that S1 was decreased with increasing LI (Figure 1). Prayitno et al. (1997) also found a decrease in Sl, Dz, and pecking occurred with increased intensity in the RD, but not the blue light. Further he also found that the bright $\mathrm{RD}$ light significantly increased Wk, stretching and feeding, particularly when it was applied early in the rearing period. Our Results were in accordance with these findings as highest Wk performed under HI. Wk was comparatively reduced when the age advances in DR and negative control treatments whereas HR treated birds were actively engaged in Wk even at week 5 (Figure 1). Highest $\mathrm{Wk}$ shown by $\mathrm{HR}$ in the evening during 29 to $35 \mathrm{~d}$. Our findings were supported by Buyse et al. (1996) who found that low intensities have been associated with reduced $\mathrm{Wk}$ and $\mathrm{St}$, as well as with decreased incidences of fighting, feather pecking and cannibalism. Also Newberry et al. (1988) studied two levels of LI (6 and 180 lux) and reported that broilers exposed to 180 lux stood, walked and had more total activity (Et, Dr, $\mathrm{Wk}$, and St). Similarly, Wk and feeding increased with exposure to LI of 200 lux as compared to 6 lux (Davis et al., 1999). Kristensen et al. (2006) reported that use of LIs of 100 lux resulted in increased St as compared to 5 lux. Red light has enhanced feather pecking and cannibalism (Rozenboim et al., 1999; 2004). In the current study, we also found that treatment $\times$ age $\times$ day session interaction was significant $(\mathrm{p}<0.05)$ on cannibalism assessed as BI.

In addition to broilers, LI studies with laying hens and turkeys also revealed similar results with increased activity at brighter light levels (Kjaer and Vestergaard, 1999). Recently, Alvino et al. (2009) studied the impact of three levels of LI $(5,50$, and 200 lux $)$ on broiler activity and found that broilers exposed to 5 lux rested more in contrast to other intensities but $\mathrm{Wk}$ and $\mathrm{St}$ remained unaffected. Similar to our findings, Davis et al. (1999) also found that

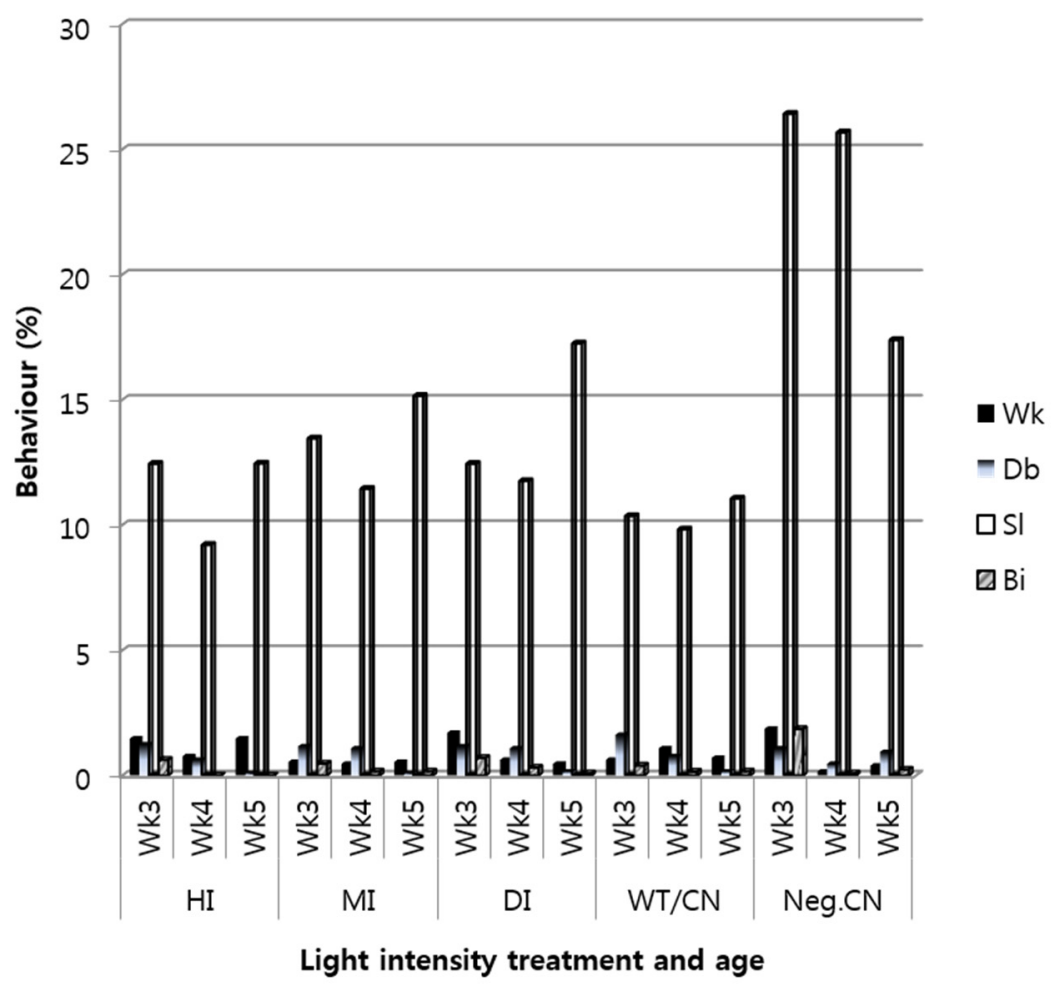

Figure 1. Proportions of time $(\%)$ spent in significantly different behaviors $(\mathrm{p}<0.05)$ under different red light intensity environments and different ages. HI, high intensity; MI, medium intensity; DI, dim intensity; WT/CN, control; Neg. CN, negative control. 
broilers exposed to 200 lux resulted in increased litterdirected behavior as compared to 6 lux. Recently, Alvino et al. (2009) showed that broilers exposed to 5 lux demonstrated reduced expression of $\mathrm{Pr}$ and foraging behavior as compared to those birds exposed to 50 and 200 lux. Overall, bright light results in increased activity. But it is unclear whether this effect is linear or there exists a threshold beyond which the activity levels remain the same as most of the previous studies, demonstrating an activity effect, used only two levels of LI (very high or low). Percentage of birds involved in Wk over the $24 \mathrm{~h}$ period and $17 \mathrm{~h}$ light phase tended to increase lineally $(\mathrm{p}=0.1)$ with increasing LI but the effect is minor. Further, the expression of Wk over the dark period was affected by LI but a specific trend was lacking and the percentage of birds involved was low (less than $0.3 \%$ ) as found by Deep (2010).

Highest $\mathrm{Db}$ showed in the morning by negative control treated birds during 22 to $28 \mathrm{~d}$. DR received the second place. Deep (2010) revealed that the birds perform $\mathrm{Db}$ when they are happy in a given situation. This indicated that either DR or negative control created much comfortable environment to perform $\mathrm{Db}$. During early days (14 to $21 \mathrm{~d}$ ), lowest $\mathrm{Db}(1.16 \% \pm 1.1 \%)$ was recorded by DR especially in the morning. Similar to this finding, Deep (2010) found $\mathrm{Db}$ over the $24 \mathrm{~h}$ and $17 \mathrm{~h} \mathrm{light}$ phase tended to be lower with 1 lux in contrast to other intensities where both preening and $\mathrm{Db}$ were almost absent during a $7 \mathrm{~h}$ of dark phase. Further, it was found that expression of stretching behavior was also affected by LI with birds exposed to 1 lux stretching less in contrast to other treatments. The percentage of birds performing feather-ruffling and wing-flapping tended to be lower with exposure to 1 lux (Deep, 2010). In the present study there was no significant effect of LI on the comfort behaviors such as W/Ls, Pr, Wf, and litter directed behaviors assessed as litter Et.

Birds were attacked each other as indicated by highest $\mathrm{BI}$ especially during evening at the age 14 to $21 \mathrm{~d}$ under negative control treatment. Therefore it is obvious that the broilers essentially require artificial light in the night to have higher WG by increasing FI and also to reduce cannibalism. Generally, brighter light will foster increased activity, while lower intensities are effective in controlling aggressive acts that can lead to cannibalism.

\section{CONCLUSION}

For better production performances, broiler birds are essentially required light especially during night. DR marginally improved body weight while compromising welfare status up to a certain extent. As FCR and most of the comfort behaviors were not significantly affected by different intensities of RL, providing HR (320 lux) to broiler chicken may be better practice to improve the welfare status. Further research are suggested to investigate a suitable lighting regimen including both high vs dim intensity RD that suits for both optimizing production and better welfare.

\section{CONFLICT OF INTEREST}

We certify that there is no conflict of interest with any financial organization regarding the material discussed in the manuscript.

\section{ACKNOWLEDGMENTS}

The work was financially supported by University Grants Commission, Sri Lanka (Reference No. UGC/ICD/CRF/2009/2/40). Prof. N.S.B.M. Atapattu and Dr. P.W.A. Perera are acknowledged for editing the manuscript.

\section{REFERENCES}

Alvino, G. M., G. S. Archer, J. A. Mench. 2009. Behavioural time budgets of broiler chickens reared in varying light intensities. Appl. Anim. Behav. Sci. 118:54-61.

Blatchford, R. A., K. C. Klasing, H. L. Shivaprasad, P. S. Wakenell, G. S. Archer, and J. A. Mench. 2009. The effect of light intensity on the behavior, eye and leg health and immune function of broiler chickens. Poult. Sci. 88:20-28.

Buyse, J., P. C. M. Simons, F. M. G. Boshouwers, and E. Decuypere. 1996. Effect of intermittent lighting, light intensity and source on the performance and welfare of broilers. World's Poult. Sci. J. 52:121-130.

Charles, R. G., F. E. Robinson, R. T. Hardin, M. W. Yu, J. Feddes, and H. L. Classen. 1992. Growth, body composition and plasma androgen concentration of male broiler chickens subjected to different regimes of photoperiod and light intensity. Poult. Sci. 71:1595-1605.

Davis, N. J., N. B. Prescott, C. J. Savory, and C. M. Wathes. 1999. Preferences of growing fowls for different light intensities in relation to age, strain and behaviour. Anim. Welf. 8:193-203.

Deep, A., K. Schwean-Lardner, T. G. Crowe, B. I. Fancher, and H. L. Classen. 2010. Effect of light intensity on broiler production, processing characteristics and welfare. Poult. Sci. 89:23262333.

Denbow, D. M., A. T. Leighton, and R. M. Hulet. 1990. Effect of light sources and light intensity on growth performance and behavior of female turkeys. Br. Poult. Sci. 31:439-445.

Downs, K. M., R. J. Lien, J. B. Hess, S. F. Bilgili, and W. A. Dozier. 2006. The effects of photoperiod length, light intensity and feed energy on growth responses and meat yield of broilers. J. Appl. Poult. Res. 15:406-416.

Ekstrand, C. and T. E. Carpenter. 1998. Temporal aspects of footpad dermatitis in Swedish broilers. Acta Vet. Scand. 39: 229-236.

Ferrante, V., S. Lolli, S. Marelli, G. Vezzoli, F. Sirri, and L. G. Cavalchini. 2006. Effect of light programmes, bird densities and litter types on broilers welfare. In: Proc. XII European Poultry Conference, Verona, Italy. 10-14 sept 2006. Word's 
Poult. Sci. J. 62 (supplement):586.

Hullet, R. M., D. M. Denbow, and A. T. Leighton. Jr. 1992. The effect of light sources and intensity on turkey egg production. Poult. Sci. 71:1277-1282.

Kestin, S. C., T. G. Knowles, A. E. Tinch, and N. G. Gregory. 1992. Prevalence of leg weakness in broiler chickens and its relationship with genotype. Vet. Rec. 131:190-194.

Kjaer, J. B. and K. S. Vestergaard. 1999. Development of feather pecking in relation to light intensity. Appl. Anim. Behav. Sci. 62:243-254

Kristensen, H. H., J. M. Aerts, T. Leroy, C. M. Wathes, and D. Berckmans. 2006. Modelling the dynamic activity of broiler chickens in response to step-wise changes in light intensity. Appl. Anim. Behav. Sci. 101:125-143.

Lien, R. J., J. B. Hess, S. R. McKee, S. F. Bilgili, and J. C. Townsend. 2007. Impact of light intensity and photoperiod on liveperformance, heterophil to lymphocyte ratio and processing yields of broilers. Poult. Sci. 86:1287-1293.

Lien, R. J., J. B. Hess, S. R. McKee, and S. F. Bilgili. 2008. Effect of light intensity on live perfeormance and processing characteristics of broilers. Poult. Sci. 87:583-857.

Martin, P. and P. Bateson. 1993. Measuring Behaviour: An Introductory Guide. Secnd. Editn. Cambridge University Press, Cambridge, UK.

Newberry, R. C., R. J. Hunt, and E. E. Gardiner. 1985. Effects of alternating lights and strain on behaviour and leg disorders and sudden death syndrome of roaster chickens. Poult. Sci. 64:1863-1868.

Newberry, R. C., R. J. Hunt, and E. E. Gardiner. 1988. Influence of light intensity on behaviour and performance of broiler chickens. Poult. Sci. 67:1020-1025.

Prayitno, D. S. and C. J. C. Phillips. 1997. Equating the perceived brightness of blue and red lights to hens. Br. Poult. Sci. $38: 136-141$
Prayitno, D. S., C. J. C. Phillips, and H. Omed. 1997. The effects of colour of lighting on the behaviour and production of meat chicken. Poult. Sci. 76:452-457.

Rozenboim, I., I. Biran, Z. Uni, and O. Halevy. 1999. The involvement of onochromatic light in growth, develooment and endocrine parameters of broilers. Poult. Sci. 78:135-138

Rozenboim, I., I. Biran, Y. Chaisena, S. Yahav, A. Rosenstrauch, D. Skian, and O. Halevy. 2004. The effect of green and blue monochromatic light combination on broiler growth and development. Poult. Sci. 83:842-845.

SAS. 2003. The SAS System for Windows, Release 9.1.3Service pack 2, TS-level 01M3.SAS Institute Inc., Cary, NC, USA.

Senaratna, D., T. Samarakone, A. A. P. Madusanka, and W. W. D. A. Gunawardane. 2012. Preference of broiler chicken for different light colours in relation to age, session of the day and behaviour. Annual Congress, PGIA, University of Peradeniya. (Proc.P6) J. Trop. Agric. Res. 23:193-203.

Senaratna, D., T. Samarakone, A. A. P. Madusanka, and W. W. D. A. Gunawardane. 2011. Performance, behaviour and welfare aspects of broilers as affected by different colours of artificial light. Published by Faculty of Agriculture, University of Ruhuna. J. Trop. Agric. Res. Ext. (TARE) Vo. 14(2).

Senaratna, D., T. Samarakone, N. S. B. M. Atapattu, D. R. Paranawithana, and W. C. J. Chandrasiri. 2010. Light colour preference in broilers reared intropical environment. Proc. $7^{\text {th }}$ Academic Sessions, University of Ruhuna, Matara, Sri Lanka. p 114.

Wathes, C. M., H. H. Spechter, and T. S. Bray. 1982. The effects of light illuminance and wavelength on the growth of broiler chickens. J. Agric. Sci. Cambridge, 98:195-201.

Weeks, C. A., T. G. Knowles, R. G. Gordon, A. E. Kerr, S. T. Peyton, and N. T. Tillbrook. 2002. New method for objectively assessing lameness in broiler chickens. Vet. Rec. 151:762-764. 